\title{
Using parent metaphors for learning about the neonatal care experience: an interpretive perspective \\ Julia Petty
}

\begin{abstract}
This study focuses on how metaphors are used by parents who have had a premature baby, to describe their neonatal care experience and how these can contribute to empathic learning of health professionals. In health, metaphors are commonly used to communicate and explain difficult topics. When patients tell their story, metaphor can be a means of expression from which we can learn about their experience of illness or hospitalisation. Limited research exits on how metaphor can improve our understanding of parent's emotional experience in neonatal care and subsequently inform education in this field. Employing narrative inquiry within an interpretive, constructivist paradigm, twenty narrative interviews with twenty-three parents of premature babies were analyzed using a process of metaphor identification.

Findings revealed common metaphors used to describe experience. Metaphor clusters used by parents in order of frequency were: journeying, altered reality, darkness, breaking, connections, fighting, salvation and being on the edge. Parents widely used compelling and emotive metaphors to describe and express both difficult and challenging times as well as progression forward. Metaphors serve as a powerful way for health professionals to learn about the emotional experiences of parents and potentially enhance their empathic understanding.
\end{abstract}

\section{INTRODUCTION}

Experiencing the birth of a premature neonate and the subsequent admission to the neonatal unit presents parents with significant emotional challenges which are widely documented (Aagaard and Hall, 2008; Turner et al., 2014; Spinelli et al., 2016). Understanding parents' 
experiences is a fundamental part of being able to deliver empathic, person-centred care that focuses on humanistic, emotional needs as well as physical needs. In healthcare, attending to the narratives of patients, carers or parents has proven to be an effective way for health professionals to hear and see some of what they experience and to be able to empathise with them (De Vecchi et al, 2016; Hardy and Sumner, 2018). Metaphors can enable patients to express their experience as they tell their stories, opening many emotions (Petty, 2017) which in turn, can elicit an emotional response that connects the listener with the storyteller (Bleakley, 2017). Experience described in the form of metaphor is said to form a common language to help health professionals understand, for example, what it is like during an oftenprotracted stay in hospital with a sick baby or child (Beck, 2017), a situation many parents in neonatal care can resonate with. The research reported in this paper is one part of a larger, ongoing study that explored the potential value of parent narratives to engender empathic learning in neonatal nurses and health professionals. Based within a narrative, interpretive theoretical framework, the current paper will focus specifically on how parents describe their neonatal experience using metaphors, to inform and educate.

\section{BACKGROUND}

Metaphor is defined in the context of this study as a figure of speech that uses concrete expression to convey the meaning of an abstract concept (Mustacchi and Krevans, 2001). Within healthcare, the language used by patients or parents to explain their healthcare experience is important as it frequently contains figures of speech which can be invaluable to gain a fuller understanding of one's experience and /or the clinical picture (Khullar, 2014; Southall, 2013). Metaphors can also help people make sense of emotional experience particularly as language can be an important mechanism for representing and explaining uncertainty (Appleton and Flynn, 2014; Periyakoil, 2008). This is key to the area of neonatal 
care where making sense of and understanding parents' emotional experience including difficult and challenging times is important to give sensitive care tailored to their needs (Obeidat et al, 2009; Fleck, 2016).

Within the neonatal field, research has explored parent perspectives in relation to experience. Emotional stress, anxiety and challenges such as uncertainty and fear of future outcomes are common themes that are well documented (Turner et al, 2014; Weis et al, 2015; Banerjee et al, 2018). Only limited, qualitative research however has explored how parents describe their emotional experience in relation to language per se. An early paper written by a parent of a premature baby described her experience in relation to metaphors, including how it was like a roller-coaster when referring to the difficulties of navigating through the neonatal unit (Layne, 1996). Similarly, in a study of factors affecting coping ability in neonatal care, parents referred to this 'roller coaster' in relation to their emotions (Stacey et al, 2015), highlighting the highs and lows of their experience; periods of hope followed by uncertainty and fear. Parents in Kantrowitz-Gordon and Vandermause's (2016) study used photographs from their children's photo history in the six month period since their premature birth to produce rich metaphors representing their distress as parents. The study concluded that metaphors can explain the gravity of distress in a way that is accessible to those who have never experienced premature birth. Common metaphors to describe the emotional distress were 'going through a tunnel' to depict the darkness they felt and 'feeling like robot' to describe how they felt numb and lacking in emotion. Separation from their baby at birth for admission to the neonatal unit felt like being like 'cut from balloon strings'.

This separation was also expressed metaphorically by Aagaard and Hall (2008); in a study exploring mothers' experiences of premature birth. Metaphors were used to describe the 
reciprocal relationships between mothers and their babies ("from their baby to my baby"), maternal caregiving and referred their role as moving from silent vigilance to advocacy. Fenwick et al (2008) concluded that 'becoming connected' was a significant finding when mothers spoke about their ability to parent their baby in neonatal care, concurring with the findings of Fleck (2016) and Flacking et al (2016) regarding parental distress exhibited when such connections and 'emotional closeness' were not possible.

Such depth of emotion was also seen in the narratives of the parents in a study of posttraumatic stress disorder (PTSD) following traumatic birth. This study did not focus on premature birth per se. However, it revealed nine common metaphors that provided rich insights into the experience of PTSD due to childbirth; namely, feeling like a mechanical robot with the experience being like a ticking time bomb, an invisible wall, a video on constant replay, enveloping darkness, a dangerous ocean, a thief in the night, a bottomless abyss, and as suffocating layers of trauma. More recently, Beck (2017) explored the metaphors used by parents of babies born with obstetric brachial plexus injury specifically. While research has highlighted significant information needs in parents of babies with this condition (van der Holst et al (2018), conversely, it was found that metaphors assisted mothers to express what they could not verbalise using medical terminology, providing useful insight for staff in understanding their perspectives. Again, while this study did not focus on prematurity, a powerful 'dagger in the heart' metaphor summarises the depth and intensity of emotion expressed by these mothers caring for a baby with a specific physical condition.

The above studies reveal potent metaphors which impart insight into the emotions and experiences of parents. However, previous work has not focused on the use of metaphors within an educational perspective. The impact on learning is important in the context of this 
study and the question is posed: How do parents describe their neonatal experience using metaphors and what can we learn from this?

\section{METHODS}

Aim

The aim of this study was to describe the use of metaphors by parents, for nurses and health professionals to understand and learn about their experience. In turn, it is hoped the findings will inform future development of learning resources in the neonatal field. This study in context, as a component of a larger one is depicted in Figure 1. The other study components are reported separately (Petty et al, 2019a, 2019b).

Figure 1: Metaphor analysis in the context of the main study

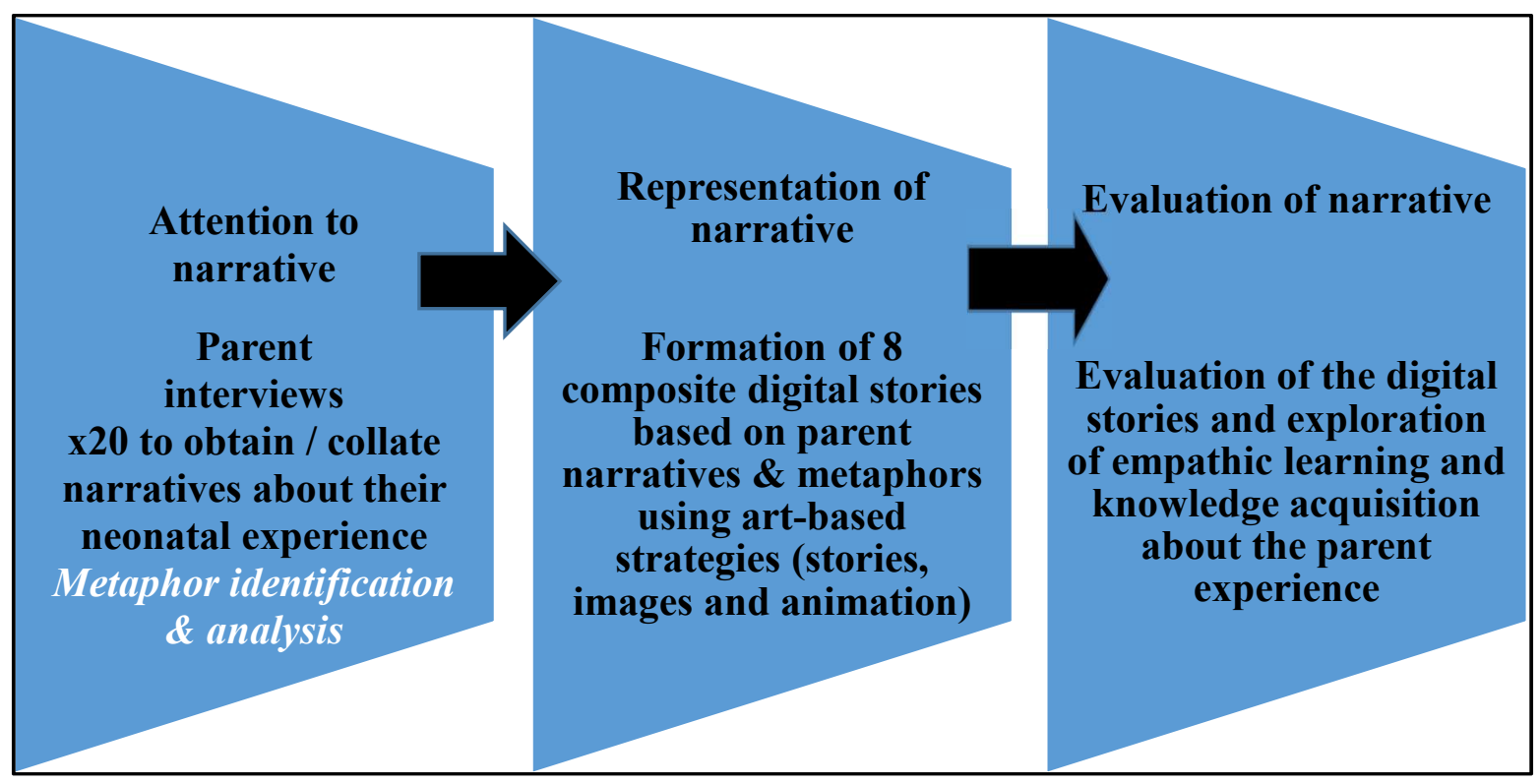

\section{Design}

The study design adopted an interpretive, narrative approach which explores the meaning of one's experience. The intent of interpretive exploration in this study was to assign meaning to the narratives of parents to acquire knowledge about their experience. Interpretivism is 
aligned with constructivist learning theory where meaning making is central and an emphasis is placed on the creation of knowledge. Narrative inquiry is also congruent with interpretivist design where there is a focus on individual, human experience actualised through narrative (Bruner, 1992). This concerns how people make sense of their experience and their own world from which they or others can learn from (Clandinin and Connelly, 2000; Riley and Hawe, 2005; Price, 2011). Figure 1 depicts how the researchers sought to uncover an understanding of parents' experiences based on interpretation of their narratives through metaphorical language.

\section{Participants and recruitment}

Purposive sampling through identified gatekeepers from a UK parent charity was used to request and recruit volunteers into the study to be interviewed. Participants were selected based on certain characteristics; parents whose babies had been born prematurely (before 37 weeks gestation) and discharged home. Inclusion criteria were intentionally broad as the aim was not to generalise the findings; rather, it was to gain deeper understanding of a varying range of experiences and stories of the participants, to use for learning and teaching purposes. Being too restrictive would have potentially prevented a varying range of experiences and stories. Exclusion criteria therefore were limited to parents whose babies were born after 37 weeks gestation and had spent less than a week in neonatal care. No restriction was imposed on who could tell their story between mothers and fathers, as again the aim was to gain both perspectives in the above-mentioned context of offering a variety of different experiences. In the mother-father pairs, both parents contributed to telling their stories. 
Recruiting through a volunteer basis meant limited control of the specific parent characteristics of those who came forward to tell their story, such as parent gender, age, ethnicity or the time frame within which babies and parents had been discharged. It was acknowledged that these factors may have influenced the experiences reported. In relation to the time at interview however, each story had something unique to offer and even parents who had been discharged within the preceding ten-year period were able to recall their experiences lucidly. In terms of the number of participants in the study, recruitment continued until the decision was by the researchers that data saturation had been reached.

Overall, twenty-three participants were recruited to the study comprising sixteen mothers, one father and three mother-father pairs. Between them, the parents had a total of twenty-seven premature babies. Details of participants are outlined in Table 1. Twenty narrative interviews were undertaken. Narrative interviewing is a way to collect participant stories about experiences and do not have a rigid format, allowing the participant being interviewed to have control over the content, direction and pace of the interview (Anderson and Kirkpatrick, 2016). The interviews took place within the parents own home or an agreed location lasting between sixty and one hundred and five minutes. Written consent was taken prior to all the interviews. A broad opening question asking the parents to 'tell their story' from pregnancy to the current day was given at the start of the interview. Therefore, the metaphors taken for analysis were the parents' own words as they told their stories, spontaneously revealed rather than being elicited from specific interview questions.

All interviews were recorded using a digital voice recorder and transcribed manually by the first author to enable immersion in the data and familiarisation with the content. The second and third authors verified the processes described above and the data interpretation. In 
addition, transcripts were sent to and verified by the parents themselves. These strategies are important to ensure trustworthiness and authenticity of the data.

The study received ethical approval by the first author's higher education institution (HEI) and is also compliant with the consolidated criteria for reporting qualitative research (COREQ) (Tong et al, 2007).

\section{Analysis}

Following interview transcription, metaphor analysis was undertaken. Different approaches are documented for such analysis. For example, Lakoff and Johnson's (2003) seminal work on metaphor analysis, describes a cognitive, linguistic model which they postulate, can reveal patterns of both thought and action. Cameron has analysed qualitative-based narratives and proposed that the distribution of metaphors shows clustering at certain points (Cameron, 2012; Cameron and Maslen, 2010). However, these above models are based on discourse analysis. The area of interest in this study is understanding experience and not the structure of language or discourse. Even Lakoff and Johnson acknowledge that metaphors are not just linguistic constructs but expressions of the structure of individual's thoughts (Lakoff and Johnson, 2003).

Therefore, more relevant to the current study was a descriptive form of metaphor analysis. Subsequently, the analysis used was consistent with the work of Beck $(2016,2017)$ who used Pragglejaz Group's (2007) Metaphor Identification Procedure (MIP). Central to this is the 'corpus' which is text that comes from natural language use (Charteris-Black, 2004). In this case, this was the interview transcripts from parents consisting of 122 pages of typed text. The MIP included the following steps: 
1. The text was read in full to ascertain an understanding of the content and meaning.

2. The lexical units were determined, defined as is a single word, a part of a word, or a chain of words. In the context of this study, single words were the unit of analysis; therefore, 'word' will be referred to rather than lexical unit.

3. (a) For each word, the context was considered, then; (b) whether it had a different meaning in other contexts and, (c) if the meanings in the different contexts contrasted but could be understood.

4. If yes, then this was deemed metaphorical.

An example of this approach is below:

'It/was/like/ being/in/a/long/dark/tunnel/It/was/suffocating/and/I/felt/trapped'. The context here was a mother's account of the neonatal environment. The words 'long', 'dark' and 'tunnel' combined had a different meaning to their real (usual) context when contrasted. However, this was understood as being how it made her feel. Feeling like she was suffocating and trapped continued this metaphorical explanation of the environment.

Another example was:

'He/was/next/to/me/but/so/far/away/almost/in/another/world/that/we/were/not/part/of/and/I/ couldn't/reach/him.' The context in this example is a father speaking about the immense barrier between him and his baby. The words 'far' and 'away' along with 'another' and 'world' had different meanings to their usual context but understood in relation to the father's emotions at not being able, metaphorically speaking, to feel close to his son.

Overall, the words spoken in these sentences, were regarded as being used metaphorically. This process was applied throughout all transcripts. After all the words being expressed metaphorically were identified, they were categorised into the metaphor clusters most often used by the parents. 


\section{RESULTS}

Overall, the pervasive use of metaphors by parents was evident. It was not anticipated at the outset that metaphors would be so prevalent; they arose from the parent's descriptive language and were frequently and consistently present in all interview narratives. Metaphors generated interesting and revealing insights and contributed to understanding much more than just 'what happened'. Table 2 outlines the most common metaphor clusters (1-8) in order of frequency along with their occurrence. The eight most commonly used metaphor clusters, in order of frequency were: journeying, altered reality, darkness, breaking, connections, fighting, salvation and being on the edge. Selected extracts of metaphorical expression used by parents to describe experiences are now presented. Table 3 contains selected quotes for each theme.

\section{Journeying metaphors}

By far the most common cluster found in this study were journeying metaphors, used to express parents' circumstances through a course of time. This journey was often portrayed as a tumultuous and challenging ride or a course through hurdles and barriers. The term 'longhaul' was used by three parents. Conversely, journeys for some gave opportunities for personal growth and hope and the move towards a final destination.

\section{Altered reality metaphors}

Entering the neonatal unit and being part of it for a considerable length of time often led to parents describing the experience as somehow not being real or being in another world. Frequent word counts were evident in the data for 'surreal', 'altered reality', different or another 'world'. Parents also often described their baby in non-human terms; i.e. as different to actual human reality- for example, animals and objects were commonly used: 'little scrap', 
a 'ball with wires', a 'doll', 'tiny thing', a 'tiger'. Parents also regularly linked this with difficulties or barriers to bonding. Such language may have been a way to self-protect from the reality of seeing their baby so sick, so unexpected and stressful in terms of what they had to see their own baby experience.

\section{Darkness metaphors}

The neonatal unit was often regarded as a dark place where parents felt trapped, imprisoned, institutionalised and isolated. The darkness portrayed here was often very profound and was revealed when parents spoke about the worst times during the neonatal care experience; for example, during periods when their baby was the sickest and may not have survived. However, hope and positive outcomes were conversely regarded as coming into the 'light'.

\section{Breaking metaphors}

Related to the journeying metaphors, were those referring to crashing and breaking down in some way, often after discharge when awareness of the emotional turmoil experienced in the neonatal unit came to fruition and realisation set in. This was a metaphor cluster that had solely negative meanings in relation to strong emotions and the toll that these had on parents.

\section{Connection metaphors}

Parents voiced times when they were unable to bond or connect with their baby but also the opposite, when they felt emotionally close highlighting both negative and positive metaphors. Metaphors of a bittersweet experience were voiced in relation to connecting with their babies. Mixed emotions were communicated as being both positive and negative together; for example, when babies moved to other units or parts of the unit or went home; feelings of joy and elation were mixed with dread and fear. 


\section{Fighting metaphors}

The use of military metaphors by parents related to the perceived battle going on between the vulnerable baby 'fighting the odds' and coming through the various conflicts or challenges along the way. Again, strength came out here too in relation to that of their baby. Generally, this cluster had very positive connotations rather than seeing this as overly negative. Negative metaphors related to some conflicts encountered with staff in relation to differences of viewpoint or not being listened to, but these occurrences were not frequent.

\section{Salvation metaphors}

Balancing the negative metaphors seen above, were ones speaking positively about 'being saved' particularly in relation to how parents were treated by neonatal staff. 'Investment' in terms of time and emotional support by staff made for perceptions of better outcomes in the future. In addition, while the baby may have been 'dehumanised' in many cases, there was also the strength that parents saw within their baby- i.e. the baby themselves gave them strength to carry on.

\section{Being on the edge metaphors}

With many parents, there was a consistent feeling of being 'on the edge' of something awful happening when speaking about their baby particularly in relation to whether they would survive or not. As for the breaking and crashing metaphors, this feeling continued for many, way past discharge and into the community experience.

\section{DISCUSSION}

The findings from the descriptive analysis of metaphors can inform us about the parent experience to further support other interpretive research in the neonatal field. Studies in other 
fields of nursing have found how metaphor can be a powerful expression of emotion and experience (Jairath, 1999; Shinebourne and Smith, 2010; Warne and Stark, 2004;

Laranjeira, 2013). The words and metaphors employed by patients often emphasise their emotional response to care and helped patients explain the depth of feeling about their experiences (Richardson and Grose, 2009), as seen in the current study. The metaphors revealed in this study add to findings from limited neonatal research highlighted earlier. Layne (1996) similarly to this study, described three journeying metaphors to represent her experience as a mother; roller-coaster (referring to the ups and downs of care), graduation (the progression of the baby through care) and course (likening care to navigation with hurdles to cross). Stacey et al's (2015), participants also talked about feelings of anxiety, guilt, tiredness, apprehension and joy characterised as a 'roller coaster of emotions' (pg. 138). Kantrowitz-Gordon and Vandermauses' (2016) participants described emotional distress as a journey through a tunnel and the separation at birth as being cut from the strings of a balloon in relation to broken connections, highlighted also by parents in this study. Separation and a deep need to be 'connected' with their baby along with the desire to feel like a real parent while 'struggling to mother' was also expressed metaphorically by Aagaard and Hall (2008) and Fenwick et (2008). Beck's (2017) study referred to seven metaphors from parents in relation to caring for a baby with brachial plexus injury; namely, being in a maze, juggling, a heavy weight, a dagger in the heart, a simmering pot, and once again, being on a 'rollercoaster' and in a 'battle'.

As well as commonalities, different metaphors have emerged from this study such as being in an altered reality or another world, being on the edge and breaking or crashing, highlighting both immediate emotional challenges as well as the potential ongoing effects of their experience. It was not the intention to be overly negative in the reporting of the emerging 
themes. Certainly, positive metaphors must be recognised too, as seen within the quotes themselves where elements of positivity, hope, engagement, relationships also come through. Acknowledging this balance is important (Petty et al, 2019b). Beating the odds and battling through, for example, were positive threads amongst the turmoil and stress. Literature also uses positive expressions of language such as parents being the 'first layer in the relationship surrounding their baby', in relation to them being an advocate and protector (pg. 165; So et al, 2014). Having said this, the most frequently occurring metaphor clusters did have more negative connotations in relation to difficult and challenging times, hence why this is reflected in the reporting.

The findings have implications in relation to the role and usefulness of metaphors within neonatal care and education. Being able to express experience using metaphors can help both parents and those who care for them to make sense of this experience, enabling a poignant and evocative way to communicate. This is vital given the evidence on the emotional turmoil experienced by parents and the challenges in relation coping with the stress and certainty of having a sick, premature baby (Turner et al, 2014; Spinelli et al, 2016) when emotional support can sometimes be perceived to be lacking (Bagge et al, 2017).

In addition, the need for effective communication as identified by parents (Obeidat et al, 2009; Weis et al, 2015; Flacking et al, 2016) as well as partnership and collaboration between nurses and parents (Trajkovski et al, 2015) are important areas. Metaphors may serve to overcome communication barriers when parents are faced with difficult explanations. In such cases, concrete language may not be enough for them. This was seen in the parents' narratives within the current study in that metaphors enabled parents to express how they felt at challenging moments during their neonatal experience with their sick, premature baby. 
Another element of metaphor in relation to verbalising difficult emotional issues was the way in which they bought distance to the parent's experiences. Avoiding the harsh language of uncertainty of survival, metaphor allowed parents to speak about their feelings in a different way. Spall et al (2001) agree that people use metaphors to avoid using difficult words like death and so are then able to express how they feel without using words which may upset them or others. However, one can also argue whether this avoidance of expression of emotion is to be welcomed and that this may lead to people not being truly open about their feelings.

\section{Limitations}

The limitations of this study need acknowledging. Disadvantages can be associated with an interpretivist approach regarding subjectivity of data and inferred meaning. Critique of interpretive work of this nature often refers to potential bias due to inaccurate interpretations and small participant numbers. In addition, in this study, the participants were not representative of a range of different backgrounds due to the volunteer nature of recruitment. However, qualitative work does not aim to generalise as it is based on exploration and understanding of personal experience. Rigour was addressed earlier in terms of the strategies employed to 'cleanse' the data and maximise authenticity and 'truth'; for example, sending the original transcripts back to the parents themselves to verify the interpretations, gain feedback from them and employing reflexivity.

\section{Implications for practice}

Given the emotional needs highlighted, nurses, health professionals and indeed students learning about this area of practice can gain knowledge about what parents experience to inform more empathic care. Indeed, studies show that metaphors can assist students to understand new, complex concepts in nursing education (Faulk and Morris, 2010). Nurse educators can use metaphors in planning learning activities to enable student and staff 
visualisation of ideas and concepts. This is applicable to the notion of metaphors and their contribution to learning, in line with what Clark and Rossiter (2008) and Gazarian (2010) call narrative pedagogy. Condon (2012) applauds the use of metaphors to enhance teaching and learning stating they have a real educational value, often untapped.

Since metaphors can represent a powerful expression of emotions, there is value in teaching students and staff about these emotions so that care is given in a person-centred, humanistic way. Literature concurs, highlighting the need for staff education on empathy and other elements related to parental emotional experience (Turner et al, 2014). Metaphors can give clarify and add depth to explanations and can provide an opportunity to explore topics from a creative and novel perspective. Using qualitative interview data to explore metaphors gives researchers a creative and valuable opportunity to generate new knowledge from their data. This power and opportunity held by metaphor to educate others has evoked the author's interest in using them for others to learn about the parent experience. The first author is using them now to develop parent-focused learning resources to teach others; in other words, the metaphor themes found in the parent data are forming the basis of digital stories. Three examples of digital stories that have been developed, based on the identified metaphor themes, are below:

○ 'Another World' https://youtu.be/V h-5X9D6gM

○ 'On the Edge' https://youtu.be/kEFtB1Ke0fc

○ 'Fighter' https://youtu.be/jKHXdVjXEcc

These videos are now part of a collection of digital stories to be hosted on a web-based platform (https://neonatalstories.com/parent-stories) and used for educational purposes. No prior study to date to the author's knowledge has explored the use of stories based on parent narratives and metaphors, that can be used for learning and teaching for learners, nurses and 
health professionals in this field. This re-iterates the potential educational value of the current study.

\section{CONCLUSION}

This paper makes a case for the value of using metaphors when describing the emotional experience of parents in neonatal care. Metaphors provide a unique opportunity to learn about the parent experience. They allow researchers, nurses and health professionals to view others' experiences with different viewpoints, by seeing what people experience and feel. Metaphors are commonly used when stories are told and are a compelling means of relaying experience as a way of opening opportunities for new, creative possibilities in learning and teaching. Southall (2013) sees metaphor as a tool of creation; this has a potential for future learning resource development based on narrative. In this study, metaphors had the power to capture and teach the complexities of the parent's emotional experience so that others can be taught to understand and empathise with them. Educators can integrate metaphors into storytelling to teach emotional care within narrative curricula, the basis of future work leading on from this current study. 


\section{REFERENCES}

Aagaard H and Hall E (2008) Mothers' Experiences of Having a Preterm Infant in the Neonatal Care Unit: A Meta-Synthesis. Journal of Pediatric Nursing 23(3): 26-36.

Anderson, C. and Kirkpatrick, S. (2016). Narrative interviewing. International Journal of Clinical Pharmacy, 38(3): 631-634.

Appleton L and Flynn M (2014) Searching for the new normal: Exploring the role of language and metaphors in becoming a cancer survivor. European Journal of Oncology Nursing 18(4): 378-384.

Bagge SR, Westgate B, Few K, Clarke P, Adlam A, Walsh J and O'Brien M (2017) Acceptability and feasibility of collecting psychosocial data from fathers of very low birth weight infants. Journal of Child Health Care 21(3), 283-291.

Banerjee J, Aloysius A, Platonos K et al (2018) Innovations: Supporting family integrated care. Journal of Neonatal Nursing 24(1): 48-54.

Beck CT (2016) Posttraumatic stress disorder after birth: A metaphor analysis. $M C N$ : The American Journal of Maternal Child Nursing 41: 76-83.

Beck CT (2017) Caring for a Child With an Obstetric Brachial Plexus Injury: A Metaphor Analysis. Journal of Pediatric Nursing 36: 57-63.

Bleakley A (2017) Thinking with Metaphors in Medicine: The State of the Art. Abingdon: Taylor and Francis.

Bruner J (1992) Acts of Meaning. Cambridge: Harvard University Press.

Cameron L and Maslen R (2010) Metaphor Analysis: Research Practice in Applied Linguistics, Social Sciences and the Humanities. London: Equinox.

Cameron LJ (2012) Metaphor and reconciliation: The discourse dynamics of empathy in post-conflict conversations. London: Routledge.

Charteris-Black J (2004) Corpus approaches to critical metaphor analysis. New York: Palgrave MacMillan.

Clandinin FM. and Connelly J (2000) Narrative Inquiry; experience and story in qualitative research. San Francisco: Jossey-Bass.

Clark MC and Rossiter M (2008) Narrative learning in adulthood. New directions for adult and continuing education, 119, 61-70.

Condon BB (2012) Metaphorically Speaking. Nursing Science Quarterly 25(4): 316-317.

De Vecchi N, Kenn, A, Dickson-Swift V et al (2016) How digital storytelling is used in mental health: A scoping review. International Journal of Mental Health Nursing 25(3): 183-193. 
Faulk D and Morris A (2010) The Perspective Transformation Journey Using a Metaphor to Stimulate Student Engagement and Self-reflection. Nurse Educator 35(2): 54-55

Fenwick J, Barclay L and Schmied V (2008) Craving closeness: A grounded theory analysis of women's experiences of mothering in the Special Care Nursery. Women and Birth 21(2): $71-85$.

Flacking R, Thomson G and Axelin A. (2016) Pathways to emotional closeness in neonatal units - a cross-national qualitative study. BMC Pregnancy and Childbirth 16(1): 1-8.

Fleck P (2016) Connecting Mothers and Infants in the Neonatal Intensive Care Unit. Newborn and Infant Nursing Reviews 16(2): 92-96.

Gazarian PK (2010) Digital stories: incorporating narrative pedagogy. The Journal of Nursing Education 49(5): 287-290.

Hardy P and Sumner T (2018) Cultivating Compassion How Digital Storytelling is Transforming Healthcare ((2nd Edition). London: Palgrave MacMillan.

Jairath N (1999) Myocardial infarction patients' use of metaphors to share meaning and communicate underlying frames of experience. Journal of Advanced Nursing 29(2): 283-289.

Kantrowitz-Gordon I and Vandermause R (2016) Metaphors of Distress. Qualitative Health Research 26(8): 1031-1043.

Khullar D (2014) The Trouble with Medicine's Metaphors. TheAtlantic.Com. Available at: https://www.theatlantic.com/health/archive/2014/08/the-trouble-with-medicinesmetaphors/374982/ (accessed 17 March 2010).

Lakoff G and Johnson M (2003) Metaphors we live by. Chicago: Chicago University Press.

Laranjeira C (2013) The role of narrative and metaphor in the cancer life story: A theoretical analysis. Medicine, Health Care and Philosophy 16(3): 469-481.

Layne L (1996) “"Hows the baby doing?"” Struggling with Narratives of Progress in a Neonatal Intensive Care Unit. Medical Anthropology Quarterly 10(4): 624-656.

Mustacchi P and Krevans JR (2001) Metaphorically speaking: the metaphor of health care provision as a factory. The Western Journal of Medicine 175(1): 14-6.

Obeidat HM, Bond EA and Callister LC (2009) The parental experience of having an infant in the newborn intensive care unit. The Journal of Perinatal Education 18(3): 23-9.

Periyakoil VS (2008) Using metaphors in medicine. Journal of Palliative Medicine, 11(6): 842-844.

Petty J (2017). Emotion work in qualitative research: interviewing parents about neonatal care. Nurse Researcher, 25(3), 26-30. 
Petty J Jarvis J, Thomas R. (2019a). Understanding parents' emotional experiences for neonatal education: A narrative, interpretive approach. Journal of Clinical Nursing. 28(910), 1911-1924.

Petty J, Jarvis J, Thomas R. (2019b). Listening to the parent voice to inform person-centred neonatal care. Journal of Neonatal Nursing. 25(3), 121-126.

Pragglejaz Group (2007) MIP: A method for identifying metaphorically used words in discourse. Metaphor and Symbol 22: 1-39.

Price B (2011) Improving clinical reasoning in children's nursing through narrative analysis. Nursing Children and Young People 23(6): 28-35.

Richardson J and Grose J (2009) The use of descriptive words and metaphor in patient and carer experience of palliative day care: secondary analysis of a qualitative study. The Open Nursing Journal 3: 18-24.

Riley T and Hawe P (2005) Researching practice: The methodological case for narrative inquiry. Health Education Research 20(2): 226-236.

Shinebourne P and Smith JA (2010) The communicative power of metaphors: An analysis and interpretation of metaphors in accounts of the experience of addiction. Psychology and Psychotherapy: Theory, Research and Practice 83(1): 59-73.

So, S., Rogers, A., Patterson, C., Drew, W., Maxwell, J., Darch, J., ... and Pollock-BarZiv, S. (2014). Parental experiences of a developmentally focused care program for infants and children during prolonged hospitalization. Journal of Child Health Care, 18(2): 156-167.

Southall D (2013) The patient's use of metaphor within a palliative care setting: theory, function and efficacy. Palliative Medicine 27(4): 304-13.

Spall B, Read S. and Chantry D. (2001) Metaphor: Exploring its origins and therapeutic use in death, dying and bereavement. International Journal of Palliative Care Nursing 7: 345353.

Spinelli M, Frigerio A, Montali, L et al (2016) 'I still have difficulties feeling like a mother': The transition to motherhood of preterm infants mothers. Psychology and Health 31(2): 184 204.

Stacey S, Osborn M and Salkovskis P (2015) Life is a rollercoaster. . What helps parents cope with the Neonatal Intensive Care Unit (NICU)? Journal of Neonatal Nursing 21(4): $136-141$.

Tong A, Sainsbury P and Craig J (2007) Consolidated criteria for reporting qualitative research (COREQ): a 32-item checklist for interviews and focus groups. International Journal of Quality in Health Care 19(6):349-357.

Trajkovski, S., Schmied, V., Vickers, M., and Jackson, D. (2015). Using appreciative inquiry to bring neonatal nurses and parents together to enhance family-centred care: A collaborative workshop. Journal of Child Health Care 19(2): 239-253. 
Turner M, Chur-Hansen A and Winefield H (2014) The neonatal nurses' view of their role in emotional support of parents and its complexities. Journal of Clinical Nursing 23(21-22):

3156-3165.

van der Holst, M., Steenbeek, D., Pondaag, W., Nelissen, R. G., and Vlieland, TPV (2018) Health-care use and information needs of children with neonatal brachial plexus palsy: A cross-sectional survey among 465 Dutch patients. Journal of Child Health Care doi: $10.1177 / 1367493518814916$.

Warne T and Stark S (2004) Service users, metaphors and teamworking in mental health. Journal of Psychiatric and Mental Health Nursing 11(6): 654-661.

Weis J, Zoffmann V and Egerod I (2015) Enhancing person-centred communication in NICU: A comparative thematic analysis. Nursing in Critical Care 20(6): 287-298. 
Table 1: $\quad$ Participant details

\begin{tabular}{|c|c|c|}
\hline \multicolumn{2}{|l|}{ Parent details (n=23) } & \multirow{2}{*}{$\begin{array}{l}\text { Number } \\
16 \text { interviews }\end{array}$} \\
\hline Interviews $(\mathrm{n}=20)$ & Mother & \\
\hline & Father & 1 interview \\
\hline & Mother \& father together & 3 interviews \\
\hline \multirow[t]{4}{*}{ Age of parent } & $18-25$ years & 3 \\
\hline & $26-30$ years & 10 \\
\hline & $31-40$ years & 11 \\
\hline & $>40$ years & 3 \\
\hline \multirow[t]{2}{*}{ Ethnicity of parents } & Caucasian & 22 \\
\hline & French & 1 \\
\hline \multicolumn{2}{|l|}{ Child details (n=27) } & Number \\
\hline \multirow[t]{4}{*}{ Gestation born } & 24-26 weeks & 13 \\
\hline & $26-28$ weeks & 3 \\
\hline & 28-30 weeks & 6 \\
\hline & 30-32 weeks & 5 \\
\hline \multirow[t]{4}{*}{ Order of birth } & $1^{\text {st }}$ child & 18 \\
\hline & $2^{\text {nd }}$ child & 6 \\
\hline & $3^{\text {rd }}$ child & 2 \\
\hline & $4^{\text {th }}$ child & 1 \\
\hline \multirow[t]{6}{*}{ Age of child at interview } & $1-2$ years & 6 \\
\hline & $2-4$ years & 8 \\
\hline & $4-6$ years & 2 \\
\hline & $6-8$ years & 4 \\
\hline & $8-10$ years & 5 \\
\hline & Died & 2 \\
\hline \multirow[t]{2}{*}{ Gender of child } & Male & 14 \\
\hline & Female & 13 \\
\hline \multirow[t]{3}{*}{ Birthweight } & 500-750 grammes & 12 \\
\hline & 750 -1000 grammes & 5 \\
\hline & $1000-1500$ grammes & 10 \\
\hline \multirow[t]{2}{*}{ Singleton or multiple birth } & Singleton & 25 \\
\hline & Twin & 2 \\
\hline
\end{tabular}


Table 2: Metaphor clusters

\begin{tabular}{|c|l|c|c|}
\hline Cluster number & \multicolumn{1}{|c|}{ Cluster title } & $\begin{array}{c}\text { Occurrence } \\
\text { (in order of } \\
\text { frequency) }\end{array}$ & $\begin{array}{c}\text { Occurrence } \\
\text { within interview } \\
\text { sources (x20) }\end{array}$ \\
\hline 1 & Travelling / journeying & 87 & 16 \\
\hline 2 & Altered reality & 59 & 12 \\
\hline 3 & Darkness and light & 58 & 10 \\
\hline 4 & Breaking and crashing & 57 & 11 \\
\hline 5 & Connection and belonging & 51 & 12 \\
\hline 6 & Fighting and conflict & 32 & 11 \\
\hline 7 & Salvation and strength & 32 & 9 \\
\hline 8 & On the edge & 20 & 9 \\
\hline
\end{tabular}

\begin{tabular}{|c|}
\hline Table 3: Selected quotes for each metaphor cluster \\
\hline Journeying metaphors \\
\hline $\begin{array}{c}\text { 'We knew it would be a long haul...... we realised what was ahead... } \\
\text { the rocky road", } \\
\text { (Interview 17, mother) }\end{array}$ \\
\hline $\begin{array}{c}\text { 'There were so many ups and downs, bumps along the way ...... sounds a cliché, but just } \\
\text { like a roller-coaster.... an apt term to describe what it was like", } \\
\text { (Interview } 11, \text { mother) }\end{array}$ \\
\hline $\begin{array}{c}\text { "We were on a long road towards going home and being together as one unit"' } \\
\text { (Interview 12, mother) }\end{array}$ \\
\hline Altered reality metaphors \\
\hline $\begin{array}{c}\text { "We entered the very different world of the neonatal unit.... nothing seemed real." } \\
\text { (Interview } 2 \text {, father) }\end{array}$ \\
\hline $\begin{array}{c}\text { It was like being in another reality.... it was surreal.... a parallel universe", } \\
\text { (Interview } 3 \text {, mother) }\end{array}$ \\
\hline $\begin{array}{c}\text { "'He didn't look real....... Looked like a bright red shiny ball in a plastic box...... being } \\
\text { whisked away from me.... not a baby"' } \\
\text { (Interview 4, mother) }\end{array}$ \\
\hline $\begin{array}{c}\text { "She was in there somewhere, a shiny little doll covered in wires and tubes, like she was in } \\
\text { an oven......... But I couldn't get to her"' } \\
\text { (Interview 10, father) }\end{array}$ \\
\hline
\end{tabular}




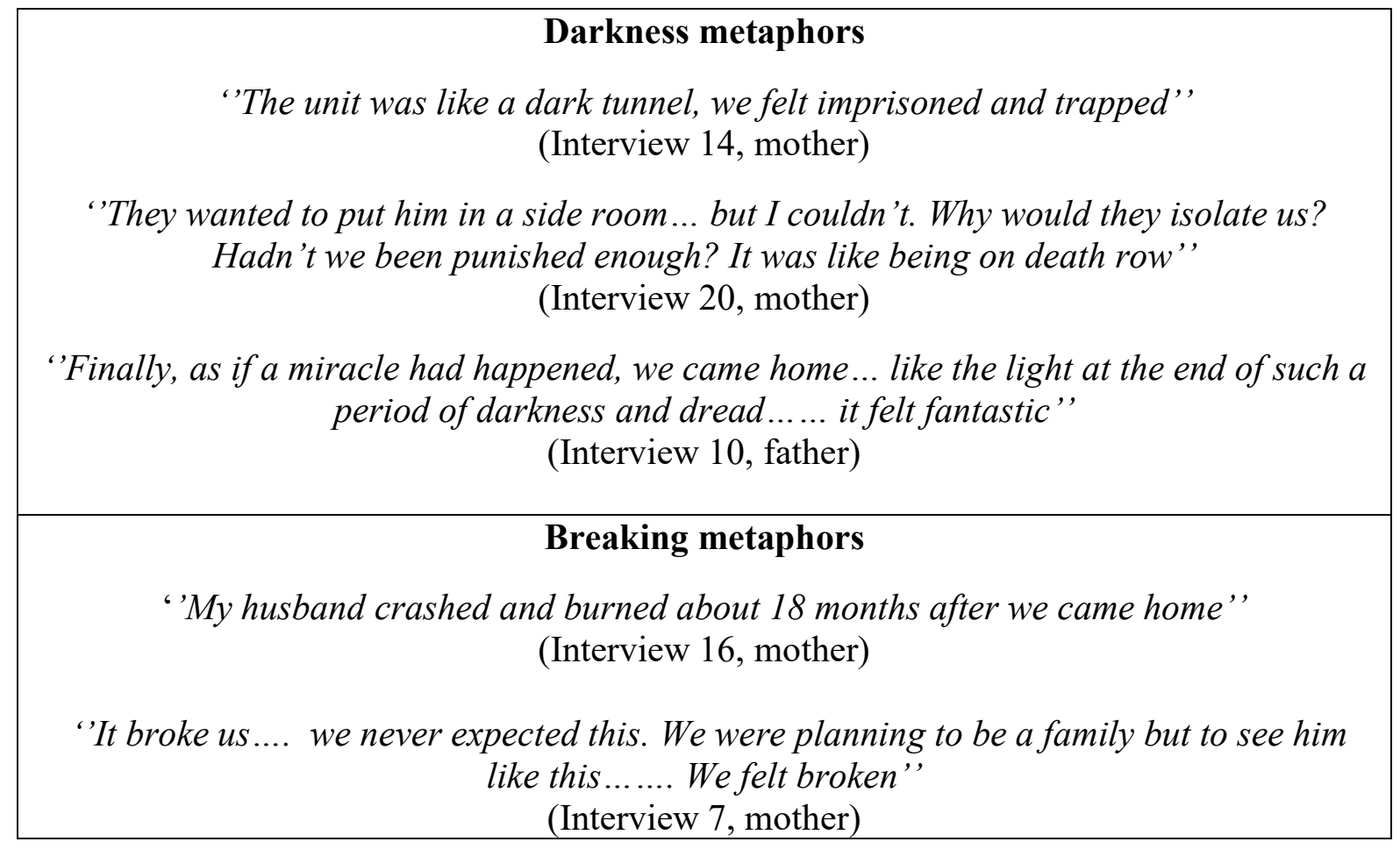

\section{Connection metaphors}

'There was my baby... in a closed box....... Separated and torn away. And I felt like I was a million miles away",

(Interview 6, father)

'The bond was broken...... I couldn't connect and there were so many barriers...', (Interview 15, mother)

"The feeling was wonderful when I held him finally... our hearts meshed together as one", (Interview 1, mother)

'Coming home was a bittersweet experience...... the support pillars came tumbling down round us but, we felt desperation to be home, to bond properly and be a family",

(Interview 19, mother)

'Feelings of happiness at my boy getting better were tinged with sadness at leaving this wonderful support system and moving to another unit',

(Interview 2, father)

\section{Fighting metaphors}

'He was such a fighter..... so small and weak and yet he fought hard and came through all the hard times.... So strong'"

(Interview 5, father)

'I called him my warrior...... he came back from the brink so many times"'

(Interview 18, mother) 


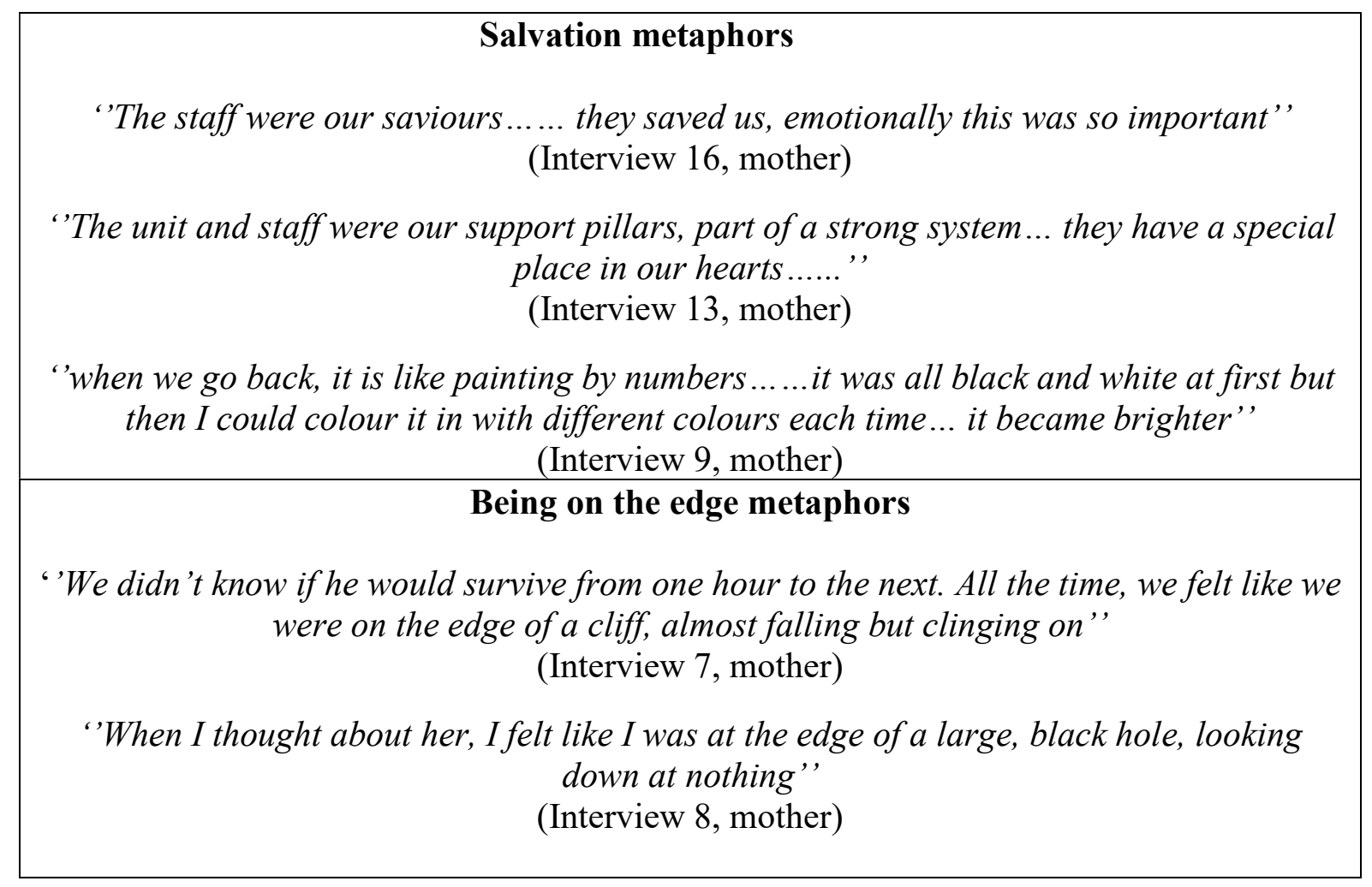

